\title{
短期間の身体トレーニングが左心形態・機能に及ぼす影響について
}

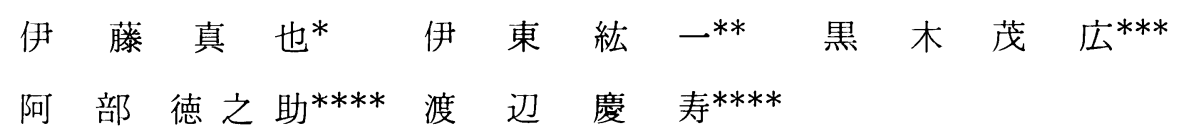

\section{EFFECT OF SHORT-TERM PHYSICAL TRAINING ON LEFT VENTRICULAR DIMENSIONS AND FUNCTION}

\author{
SHINYA ITOH, KOUICHI ITOH, SHIGEHIRO KUROKI, \\ TOKUNOSUKE ABE AND YoshiHISA WATANABE
}

\begin{abstract}
To assess the effects of short term physical training on left ventricular dimensions and function, 12 young sedentery subjects were studied with echocardiography before and after 10 weeks of endurance physical conditioning consisted of a 3000 meter running protocol 3 days a week.

Exercise training led to an increase in maximal oxygen uptake $\left(\mathrm{V}_{2} \max : 48.3 \pm 4.4\right.$ versus $60.0 \pm 6.2 \mathrm{ml} / \mathrm{kg} / \mathrm{min}: \mathrm{p}<0.001)$. This functional improvement, however, was not accompanied by any significant change in resting echocardiographic measurements including left ventricular dimensions, ejection fraction and mean velocity of circum. ferential fiber shortening.

On semi-supine exercise echocardiography no significant change was revealed after 10 weeks of physical training.

This study suggests that short term physical training in young subjects result in significant increase in $\dot{\mathrm{V}}_{2} \max$ but this functional improvement is not always associated with significant alterations in left ventricular dimensions and function as observed by echocardiogram.
\end{abstract}

(J. Physical Fitness Japan 1984, $33: 78-84$ )

I. 緒

\section{言}

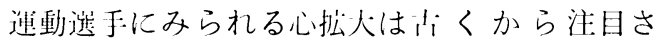
れ，その性澌をめぐって多くの破兊がなされてき だ59)ここの Athletic heart syndrome とも呼ば れる適忍状態14)は身体トレーニングに其づく二次 的変化之考えられているが遗伀的絭因の関与や必

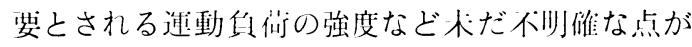
多い。また虚血性心炏忠の予队jとリハビリテーシ ョンにおける身体トレーニングの意義が浔識され るようになってとの閣題への関心はさらに高まっ てきている。近作，超音波診断装置を用いて心战
の形態的，機能的側洫を非侵熋的に評価すると とが可能となりとのう洏に多くの知見が㸃かれ た ${ }^{11)}$ 。

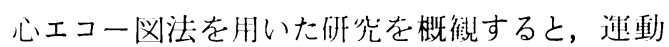
選手之一般人を比洨する cross-sectional study で!忠心形態についてほぼ一致した伯祭結果が得ら れているが心機能についての報告は椂々である。 被検者の心形態, 心㙨能をトレーニング朔後で比 洨する longitudinal study でも一定の絬果は得 られていない。そこで我々は新しい心㙨能解析法

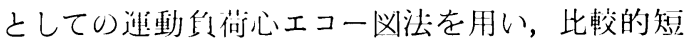
㺫閌の身体トレーニングが心形態・機能に及ぼす
* 旭川医科大学小児科

**治医科大兴臨床病理部

*** 鹿览島大学医学部附属病院

**** 自治矤科大学保健体育研究室
Department of Pediatrics, Asahikawa Medical College Department of Clinical Pathology, Jichi Medical School Medical Center, Kagoshima University Department of Physical Education, Jichi Medical School 
影響について分析を試みた。

\section{II. 対象と方法}

一般診察上健康で特别の競技歴を有しないJ矢 科大学男子学生12名（年令18１9才）在対象に将 和53年 5 月から 7 月にかけて10週間にわたり身体 トレーニングを尖施させた。トレーニングとして は週 3 (以03000 m 走を採用し最大酸素摄取量の80 \%の溞度上なる様にスピードを指示し実施した。

トレーニング䦌始 6 週目には最大酸素摄取量にあ わせてトレーニング強度を再調整しその後10週目 までこの強度を維持した。その他の日常生活には 特に制限を加えなかった。

最大酸素掑收量 $\left(\dot{\mathrm{V}} \mathrm{O}_{2} \mathrm{max}\right)$ : Monark 社製

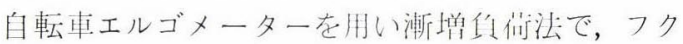
ダ社製 BMS-600 エレクトロメタボラーによる呼 気ガス連続分析值と挨父是から算治した。

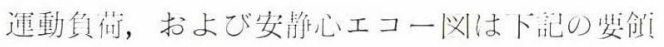
で得た。体位はエルゴメーターと椅了在組みあわ

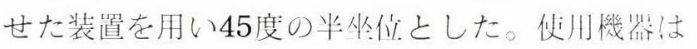
Aloka 製 SSD-100 および Honeywell 祙製の stripchart recorder で紙送り速度を $100 \mathrm{~mm} / \mathrm{sec}$ とした。2. $25 \mathrm{MHz}$ の探触子を第 $3 \sim 4$ 肋間䏫护 左:緣にあて俔帽弁前尖が打ずに热められる位监 で心到㜔と左室後壁のエコーが明暸に描出され るように設定した。同侍心電龱, 頚動脈波, 心

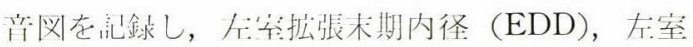

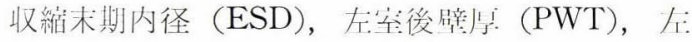
室駆出時間 (LVET) を計测した。これらから以 下の指愫を算出した。すなわち駆出径 (EDD$\mathrm{ESD}$ ), 内径变化率 (EDD-ESD/EDD), mean velocity of circumferential fiber shortening $(\mathrm{mVcf}: \mathrm{EDD}-\mathrm{ESD} / \mathrm{EDD} \times \mathrm{LVET})$ である（忟 1)。血川:は同特に上腕にて㮩診法で測定した。

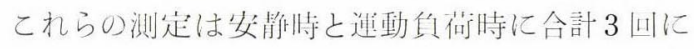

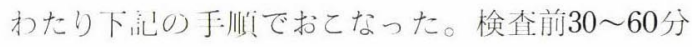

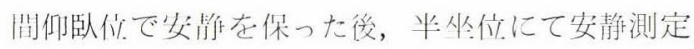
值を得た。その後エルゴメーターを $60 \mathrm{rpm} の \mid$ 回 怯数でこいで负衙圭漸次增加させながら心拍数を 锥察し，それが 100 拍/分になったところで角荷

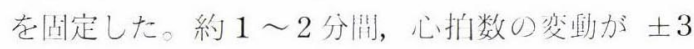
拍/30秒以内になっていることを碓認し心エコー

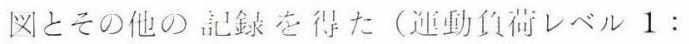

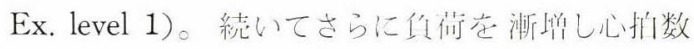
が 120 拍/分になった将点で同棁に讪銢をおこな った（運動侦條レベル 2：Ex. level 2)。

\section{III. 結果}

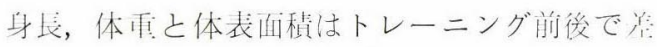
がみられなかった（表1)。广 $\mathrm{O}_{2} \max$ はトレー二 ング後に们甞の増加を走した $(\mathrm{P}<0.001$ ：表え， 汹2)。Ex. level 1 と Ex. level 2 を得るのに荘 Lた值候 (Physical Working Capacity: PWC) は10週後には塔川仳问をみせたが，統計的に有意

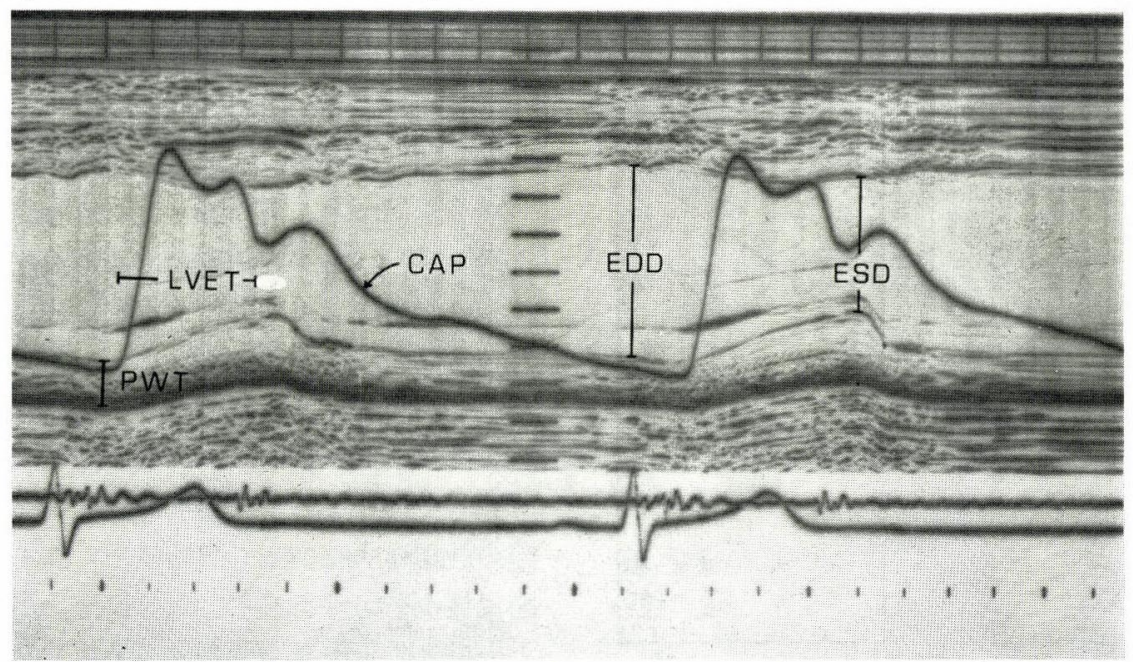

Fig. 1. Echocardiographic measurements of the left ventricle (paper speed $100 \mathrm{~mm} / \mathrm{sec}$ ). $\mathrm{EDD}=$ end diastolic dimension $; \mathrm{ESD}=$ end systolic dimension $; \mathrm{LVET}=$ left ventricular ejection time ; PWT $=$ left ventricular posterior wall thickness ; CAP=carotid arterial pulse tracing. 
Table 1. Physical characteristics before and after training (Mean $\pm \mathrm{SD}$ )

\begin{tabular}{|c|c|c|c|}
\hline \multicolumn{2}{|c|}{ Before Training } & \multirow{2}{*}{ 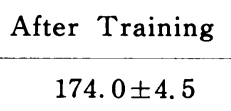 } & \multirow[t]{2}{*}{$\mathrm{P}$} \\
\hline Height $(\mathrm{cm})$ & $173.9 \pm 4.6$ & & \\
\hline Weight (kg) & $64.5 \pm 5.7$ & $63.4 \pm 4.9$ & \multirow[t]{2}{*}{ N S } \\
\hline $\operatorname{BSA}\left(\mathrm{m}^{2}\right)$ & $1.77 \pm 0.09$ & $1.76 \pm 0.09$ & \\
\hline
\end{tabular}

NS : not significant

Table 2. $\mathrm{Vo}_{2}$ max, physical working capacity and hemodynamic data (Mean $\pm \mathrm{SD}$ )

\begin{tabular}{|c|c|c|c|}
\hline \multicolumn{2}{|c|}{ Before Training } & After Training & $\mathrm{P}$ \\
\hline $\begin{array}{l}\text { At rest } \\
\qquad \dot{\mathrm{VO}}_{2} \max (\mathrm{ml} / \mathrm{kg} / \mathrm{min})\end{array}$ & 48. $3 \pm 4.4$ & $60.0 \pm 6.2$ & $\mathrm{P}<0.001$ \\
\hline HR (beats/min) & $62.7 \pm 6.0$ & $63.9 \pm 8.7$ & NS \\
\hline $\begin{array}{l}\mathrm{BP}(\mathrm{mmHg}) \\
\text { syst. /diast. }\end{array}$ & $119.6 \pm 7.4 / 70.0 \pm 8.1$ & $114.6 \pm 7.8 / 68.4 \pm 8.0$ & NS \\
\hline
\end{tabular}

Exercise level 1

\begin{tabular}{ll|l|l}
\hline $\begin{array}{l}\text { BP } \\
\text { syst. /diast. }\end{array}$ & $134.6 \pm 10.9 / 68.0 \pm 9.2$ & $135.9 \pm 11.1 / 65.8 \pm 9.1$ & NS \\
\hline PWC (kpm/min) & $308 \pm 85$ & $409 \pm 149$ & NS \\
\hline Exercise level 2 & & & NS \\
\hline BP & & $157.4 \pm 17.9 / 70.6 \pm 7.7$ & NS \\
\hline syst. /diast. & $149.2 \pm 10.9 / 66.8 \pm 7.8$ & $592 \pm 164$ & \\
\hline PWC & $476 \pm 83$ & &
\end{tabular}
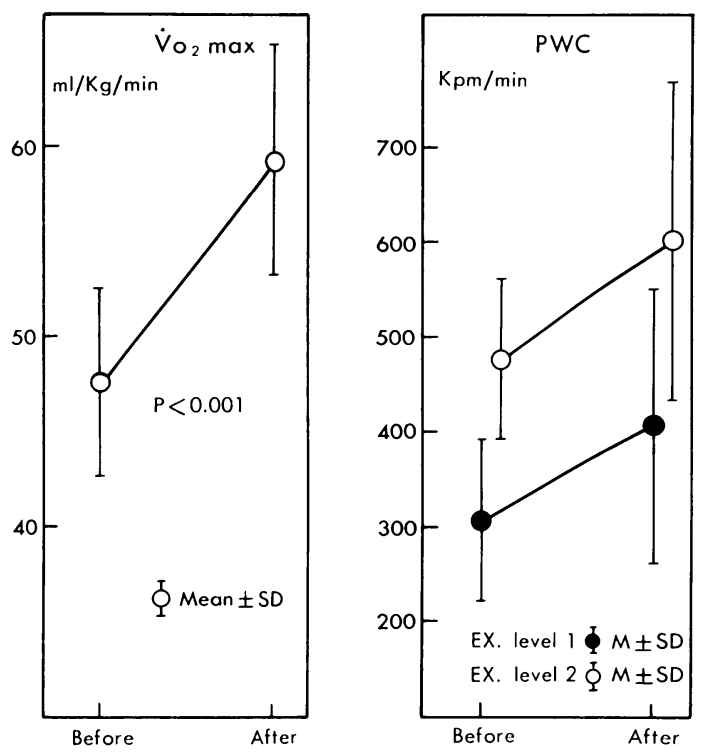

Fig. 2. Maximal oxygen uptake and physical working capacity, before and after exercise training.
ではなかった（表 2 ，図 2 )。安静時の心拍数と 血压屯10週間後には有意な变化を示さなかった。

心エコ一図より求めた各指標を表 3 と図 3 亿示 す。ただしトレーニング前の Ex. level 1 と Ex. level 2 では体動などの影響で良好な記録を得ら れず測定不能とした例がそれぞれ 2 例と 5 例あっ た。トレーニング後の記録でもそれぞれ 2 例と 7 例が計测不能であった。 $\mathrm{mVcf}$ は安静時から運動 負㫦时へと増加したがトレーニング前後で差はみ られなかった。また体動や呼吸の影響で Ex. level 2 では頚動脈波と心エコー四を同時に描出できず $\mathrm{mVcf}$ を得ることができなかった。なお心エコー 脳の計测值は原則として連続する 3 心拍以上の各 测定值の平均であらわした。以上，各指情々もた レーニング前後で有意の变化を認めなかった。

\section{IV. 考}

察

身体トレーニングが循環系に与える影響につい 
Table 3. Echocardiographic Data (Mean \pm SEM)

\begin{tabular}{lccccccc}
\hline & \multicolumn{5}{c}{ Before Training } & \multicolumn{2}{c}{ After Training } \\
\hline & At rest & Ex. level 1 & Ex. level 2 & At rest & Ex. 1 & Ex. 2 \\
\hline EDD (mm) & $47.4 \pm 0.7$ & $49.7 \pm 0.9$ & $51.3 \pm 1.3$ & $48.2 \pm 0.8$ & $49.4 \pm 0.9$ & $51.1 \pm 1.2$ \\
ESD (mm) & $32.8 \pm 1.1$ & $29.4 \pm 1.1$ & $27.7 \pm 1.5$ & $34.3 \pm 0.9$ & $30.8 \pm 1.5$ & $32.3 \pm 2.0$ \\
PWT (mm) & $10.1 \pm 0.4$ & & & $10.7 \pm 0.4$ & & \\
SD (mm) & $14.5 \pm 0.7$ & $20.3 \pm 0.8$ & $23.3 \pm 0.9$ & $13.9 \pm 0.6$ & $18.6 \pm 1.2$ & $18.6 \pm 1.6$ \\
SD/EDD & $0.31 \pm 0.02$ & $0.41 \pm 0.02$ & $0.46 \pm 0.02$ & $0.29 \pm 0.01$ & $0.38 \pm 0.03$ & $0.37 \pm 0.03$ \\
mVcf (circ/sec) & $1.00 \pm 0.06$ & $1.49 \pm 0.09$ & $*$ & $1.01 \pm 0.06$ & $1.44 \pm 0.11$ & $*$ \\
\hline
\end{tabular}

*; undetected.
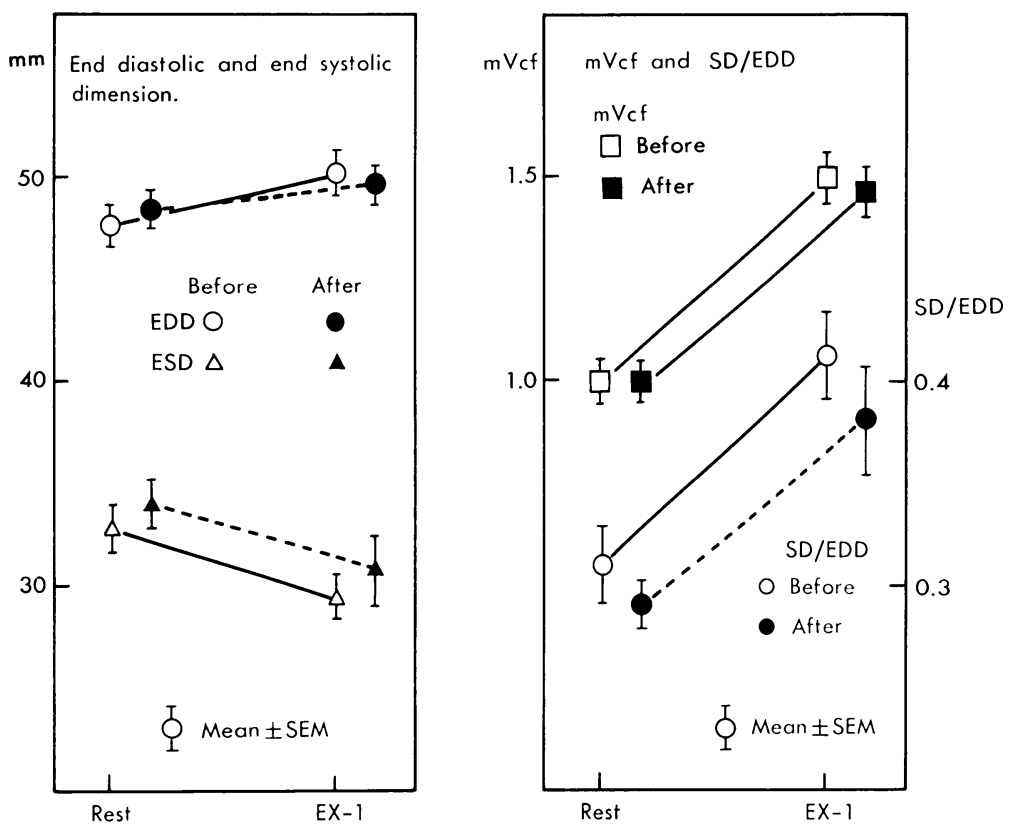

Fig. 3. Left ventricular dimensions and functional indexes derived from echocardiograms at rest and exercise level-1. Deta at exercise level-2 is not displayed.

ては従来から様々な議論がなされてきだ59)。遇 動選手を対象とした研究からは「スポーツ心臟 (Athletic heart)」といわれる生理的邀匛状態が 胸部エックス線写真や心電汹上の特徽とともに明 らかにされている21419)。なかでも胸部エックス 線写真上の心拡大についての研究は歴史が古く, 競技種目によって心拡大の程度が異なるととが 1920年代にすでに明らかにされている ${ }^{15)}$

運動選手と一般人を比較する cross sectional study では運動選手に左心搪張と心筋容量の増大 を認める点で諸家の報告は一致している 212222324)。しかし安静時心収縮能については六進
状態1722), 不変 ${ }^{23) 30)}$ そして低下状態(3)21)27) と様々 でスポーツ心臓の特徵として確立していない。身 体トレーニング前後で比較をおこなう longitudinal studyでも心昖大を認めたとするもの ${ }^{6) 8) 26)}$, 認めなかったもの710)28) があり，安静时心収繀状 態むトレーニング後に六進したとする報告6)25) 26)，不変とするもの ${ }^{8) 1028)}$ など一定していない。

Frick らは $18 \sim 19$ 才の成人 20 人を対象に 2 ケ月 のトレーニングを行い $6 \%$ の $\dot{\mathrm{V}} \mathrm{O}_{2} \max$ 増加があ ったが胸部エックス線写真上で心拡大を認めなか ったととを報告した ${ }^{10)}$ 。Wolfe らも6ケ月の身 体トレーニングにより $\dot{\mathrm{V}} \mathrm{O}_{2} \max$ は $18 \%$ 増加した 
が心エコー四上の指標には変化がなかったと報告 している ${ }^{28)}$ 。れらの理由としては, トレーニン グ強度が小さかったとと被検者の "trainability”，つまり心循環系の適応力に問題がある可 能性 ${ }^{28)}$ がそれぞれ示唆されている。

本研究では10週間の身体トレーニングで約 $25 \%$ (の) $\dot{\mathrm{V}} \mathrm{O}_{2} \max$ 増加を認めたが心形態・㙨能には有 意な変化がみられなかった。 $\dot{\mathrm{V}} \mathrm{O}_{2} \max$ 增加率を 目安にしてトレーニング強度を考えると本破筧の 場合は約25\%で他の報告6)10226)28) に比しても少く ないが，その持続剘閒は10週問であり比較的短い といえる。従ってスポーツ心臟の成立に関与する 负㫦因子としてはトレーニング嗤度だけでなくそ の持続期間も舟要之考元られる。一方，心循環系 の邀応力には作令依存性があるといわれ若年者ほ ど身体トレーニングに対しすぐれた適応を示すと されている(10)28)。胡瀬ら ${ }^{12)}$ も子文ンドボール部 过の胸部エックス線写真像から18才の高校卒業時 にすでに心拡大を認めている。また Kobayashi らによると運動選手と一般少年との $\dot{\mathrm{V}} \mathrm{O}_{2} \max の$ 装は身体成長の極期をすぎるころに急に拡大する という(8)。これらの点からスポーツ心淢の形成に は思春期前後のある期間の身体運動が重要な意味 をむつと考えられる。今回の砸究では年令からみ ると被検者の適応能は大きいと思われたが心臟白 体の变化は確認されなかった。これは若年者にお いても10週間前後の短期効果としての心臟の適応 変化はみられないか，あったとしても極めて軽微 であることを示している。今後はスポーツ心蔵形 成に関与する年令，敒候因子としてそれぞれ身体 成長期と長㥜トレーニング効果とに注目する必要 がある。

Clausen ら ${ }^{4) 5)}$ はトレーニング効果の中にはや る末梢の要系について詳䋱にのべている。それに よるとトレーニング効果としては心蔵だけでなく 㘯肉を含む朴梢领域の関与を考虑する必要がある という。短期間の身体トレーニングで心形態上の

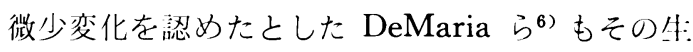
物学的甞義は不明であると述べており，本研究か らも短期間の身体トレーニングでは未梢の邀応変 化が重要である可能性が示唆された。

安静時にはとらえにくい速動時心機能，心収絎 予備能を評価する方法として動的傊㫦心エコー龱
法が注目されている1227。今回我々の用いた方法 は従来と異なり被検者を 45 度の半坐位にするもの である。また心拍数が異なる場合は心形態・機能 の比較が難しくなる為負荷を变化させて同一心拍

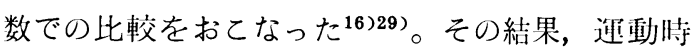
心機能・形態や体血压にはトレーニング前後で有 意の差を認めなかった。しかしトレーニング後に は同一心拍数に達するのにより大きな負衐を必要 とする傾向がみられた。

運動負荷心エコー図法の問題点は体動や呼吸の 影響により测定不能例が出現することである。 Amon ら ${ }^{1)}$ は坐位で運動負衡をした埸合に测定不 能例が $80 \%$ に達すると述べている。今回の実験で は45度半坐位であり坐位に比較して体動抑制が容 易と思われたが，それでも約 $20 \%$ の测定不能例を 認め, 強度进動負侕になるとその傾向は一屏湿著 であった。今後はさらに生理的運動状態に近くよ り再现性の優れた方法の開発が望まれる。

心エコー図はまた理論的にも方法論的にも测定

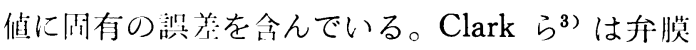
㰡患の获的肥大心を対泉に心エコー四の再现性の 目安を調べ, $\pm 3 \mathrm{~mm}$ 以上の左室搪張末期内径の 変化および $\pm 5.5 \%$ 以上の内径変化率の善を生物 学的に有意としている。この事は心エコー应上の 小さな変化の解积には充分慎重でなくてはならな いことを示している。特にトレーニング効果を論 じる場合には微少变化が問題となる壦合が多いと 考えられるのでより一層再現性を高的る工夫之蕨 密な実験計画が必要である11)。

\section{V. 結語}

若年成人男性に10週閒の身体トレーニングを実 施させ，その前後で心ェコー図等を記録し次のよ うな結果を得た。

1. 收大酸系椇取量は有意な増加を示した。

2. 安静時心形態・心機能には有意な变化を認 めなかった。

3. 迎動的荷心エコー図法ではトレーニング前 後で有意な変化を認めなかった。

本論文の一部は第33回日本体力医学会総会 (辰 野，1978）において発表した。

（受付 昭和58年 8 月13日） 
文

\section{献}

1) Amon, K.W., and Crawford, M.H. (1979): Upright exercise echocardiography. J. Clin. Ultrasound., 7, 373-376.

2) Chapman, J.H. (1977) : Intermittent left bundle branch block in the athletic heart syndrome. Chest, 71, 776-779.

3) Clark, R.D., Korcuska, K., and Cohn, K. (1980) : Serial echocardiographic evaluation of left ventricular function in valvular disease, including reproducibility guidelines for serial studies. Circulation, 62, 564575.

4) Clausen, J.P., Klausen, K., Rasumussen, B., and Trap-Jensen, J. (1973) : Central and peripheral circulatory changes after training of the arms or legs. Am. J. Physiol., 225, 675-682.

5) Clausen, J.P. (1977) : Effect of physical training on cardiovascular adjustment to exercise in man. Physiol. Rev., 57, 779815.

6) DeMaria, A. N., Neumann, A., Lee, G., Fowler, W., and Mason, D. T. (1978): Alterations in ventricular mass and performance induced by exercise training in man evaluated by echocardiography. Circulation, 57, 237-244.

7) Ditchey, R.V., Watkins, J., McKirnan, M.D., and Froelicher, V. (1981) : Effects of exercise training on left ventricular mass in patients with ischemic heart disease. Am. Heart J., 101, 701-706.

8) Ehsani, A.A., Hagberg, J.M., and Hickson, R.C. (1978) : Rapid changes in left ventricular dimensioms and mass in response to physical conditioning and deconditioning. Am. J. Cardiol., 42, 52-56.

9) Frick, M.H. (1976) : Long-term excess physical activity and central haemodynamics in man. Adv. Cardiol., 18, 136-143.

10) Frick, M.H., Sjögren, A-L., Peräsalo, J., and Pajunen, S. (1970) : Cardiovascular dimensions and moderate physical training in young men. J. Appl. Physiol., 29, 452-
455.

11) Froelicher, V.F. (1980) : Echocardiographic studies evaluating the effects of exercise training on the heart. Adv. Cardiol., 27, 51-57.

12）古瀨 信，仍藤真也，大沈忠 (1979)：又ポ 一ツ選手の心陰影, 日本厌学放射線兴会雑誌 (抄銢集)，4.

13) Gilbert, C.A., Nutter, D.O., Felner, J.M., Perkins, J.V., Heymsfield, S.B., and Schlant R.C. (1977) : Echocardiographic study of cardiac dimensions and function in the endurancetrained athlete. Am. J. Cardiol., 40, 528-533.

14) Gott, P.H., Roselle, H.A., and Crampton, R.S. (1968): The athletic heart syndrome. Arch. Intern. Med., 122, 340-344.

15) Herxheimer, H. (1929): Untersuchungen über die Änderung der Herzgrösse unter dem Einfluss bestimmter Sportarten. Z. Klin. Med., 111, 376-393.

16) Hirshleifer, J., Crawford, M., O'Rourke, R.A., and Karliner, J.S. (1975) : Influence of acute alterations in heart rate and systemic arterial pressure on echocardiographic measures of left ventricular performance in normal human subjects. Circulation, 52, 835-841.

17) Ikäheimo, M.J., Palatsi, I.J., and Takkunen, J.T. (1979) : Noninvasive evaluat-on of the athletic heart. Am. J. Cardiol., 44, 24-30.

18) Kobayashi, K., Kitamura, K., Miura, M., Sodeyama, H., Murase, Y., Miyashita, M., and Matsui, H. (1978): Aerobic power as related to body growth and training in Japanese boys. J. Appl. Physiol., 44, 666672.

19) Lichtman, J., O'Rourke, R.A., Klein, A., and Karliner, J.S. (1973) : Electrocardiogram of the athlete. Arch. Intern. Med., 132, 763-770.

20) Morganroth, J., Maron, B.J., Henry, W.L., and Epstein, S.E. (1975) : Comparative left ventricular dimension in trained athletes. Ann. Intern. Med., 82, 521-524.

21) Nishimura, T., Yamada, Y., and Kawai, C. 
(1980) : Echocardiographic evaluation of long-term effects of exercise on left ventricular hypertrophy and function in professional bicyclists. Circulation, 61, 832840.

22) Parker, B.M., Londeree, B.R., Cupp, G.V., and Dubiel, J.P. (1978): The noninvasive cardiac evaluation of long-distance runners. Chest, 73, 376-381.

23) Roeske, W.R., O'Rourke, R.A., Klein, A., Leopold, G., and Karliner, J.S. (1976): Noninvasive evaluation of ventricular hypertrophy in professional athletes. Circulation, 53, 286-292.

24) Scheuer, J., and Tipton, C. (1977) : Cardiovascular adaptations to physical training. Ann. Rev. Physiol., 39, 221-251.

25) Sheps, D.S., Gottlieb, S., Ernst, J.C., Kallos, N., Briese, F.W. Garcia, E., Myerburg, R.J., and Castellanos, A. (1979) : Effect of physical conditioning program upon left ventricular ejection fractions determined serially by a noninvasive technique. Cardiology, 64, 256-264.
26) Stein, R.A., Michielli, D., Diamond, J., Horwitz, B., and Krasnow, N. (1980) : The cardiac response to exercise training ; echocardiographic analysis at rest and during exercise. Am. J. Cardiol., 46, 219225.

27）杉下靖郎, 小関 迪, 新冨芳明 (1978)：運動 負荷と心エコ一闵法, Jap. Circ. J., 42, 3839.

28) Wolfe, L.A., Cunningham, D.A., Rechnitzer, P.A., Nichol, P.M. (1979) : Effects of endurance training on left ventricular dimensions in healthy men. J. Appl Physiol., 47, 207-212.

29) Wolfe, L.A., Cunningham, D.A., Davis, G. M., and Rosenfeld, H. (1978) : Relationship between maximal oxygen uptake and left ventricular function in exercise. J. Appl. Physiol., 44, 44-49.

30) Zeldis, S.M., Morganroth, J., and Rubler, S. (1978) : Cardiac hypertrophy in response to dynamic conditioning in female athletes. J. Appl. Physiol., 44, 849-852. 